\title{
Research of integral parameters for furnaces of a circulating fluidized bed
}

\author{
Andrey V. Gil ${ }^{1, a}$ and Alexandra Y. Gil ${ }^{2}$ \\ ${ }^{1}$ National Research Tomsk Polytechnic University, 634050 Tomsk, Russia \\ ${ }^{2}$ National Research Tomsk State University, 634050 Tomsk, Russia
}

\begin{abstract}
Modern society poses several energy problems. Improving the efficiency and reliability of power equipment and reduce the impact on the environment. The paper presents the promising technology of superheated steam using different coals. The model of the furnace with a circulating fluidized bed and numerical simulation results of gas dynamic processes using application FIRE 3D. The analysis of aerodynamics and the distribution of the dispersed phase adjustment of the furnace.
\end{abstract}

\section{Introduction}

Increase in the production of heat and power in the world community confronts several problems concerning future development of energy technologies. First of all, this increased efficiency, reliability and technological improvement of thermal power plants, and reduce the negative impact of thermal power plants on the environment.

Therefore, despite the conservatism of the generation of heat and electricity, and to achieve the seemingly limiting parameters of the working fluid with the use of the steam cycle, in which the main elements are represented boiler unit and steam turbine observed active introduction of new technologies for more efficient generation.

It may be noted that in the last decade in many countries in the process of becoming an open postindustrial society, which radically transforms the social and cultural space of human existence in the world. The introduction and use of new engineering, information and communication technology is global. And it increases the level of technology of production, the use of new forms of production process management based on innovative methods confronts modern engineers and managers to think interdisciplinary requirement categories. The main resource for the development of the individual in modern society are information and knowledge. Ability to work with databases, the amount and quality of information mastered the ability to produce new knowledge, introduce new methods in the traditional process chains [1]. In this regard, actively develop and implement technology that a few decades ago seemed ineffective having high material costs, by the globalization of knowledge and their interdisciplinary nature.

\footnotetext{
${ }^{a}$ Corresponding author: andgil@tpu.ru
}

This is an Open Access article distributed under the terms of the Creative Commons Attribution License 4.0, which permits unrestricted use, distribution, and reproduction in any medium, provided the original work is properly cited. 


\section{EPJ Web of Conferences}

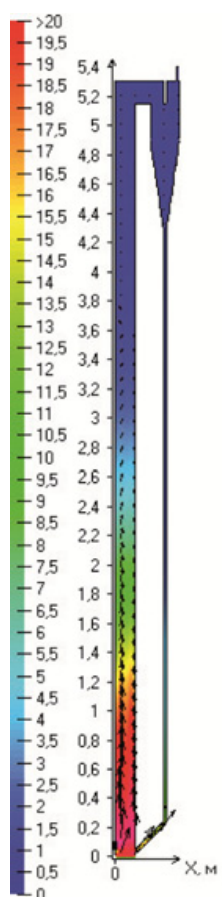

(a)

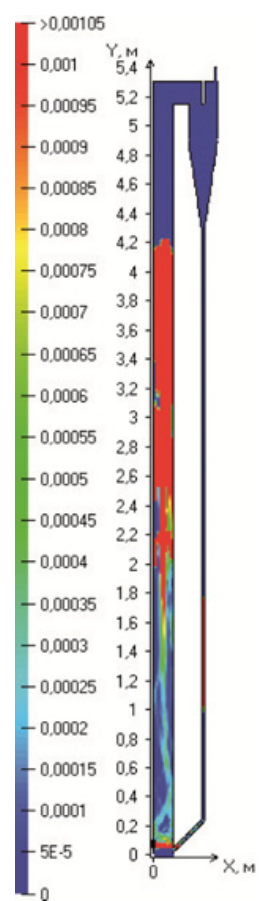

(b)

Figure 1. The results of numerical simulation models install a circulating fluidized bed (a) the change in velocity $(\mathrm{m} / \mathrm{s})(b)$ the concentration of particles $\left(\mathrm{kg} \mathrm{m}^{3}\right)$.

In the energy sector is the most promising to improve and develop coal technologies, as in the world there are more of his reserves, which in the future will be more competitive in price with respect to oil and natural gas.

\section{Problem statement}

In the US, work is underway to develop materials capable of reliable operation of power units with a pressure of $35 \mathrm{MPa}$ and temperatures up to $1143 \mathrm{~K}$.

In the EU countries are developing coal-fired boiler units for supercritical steam parameters with pressure of $37.5 \mathrm{MPa}$ steam and overheated to $993 \mathrm{~K}$. The 2030 intends to achieve efficiency of up to $55 \%$ of the steam temperature to $1073 \mathrm{~K}$.

Technology of solid fuel use based on gasification can achieve high environmental performance and at the same time, in spite of all the difficulties of the process, in recent years in the United States commissioned by experienced installation capacity of 250 and $350 \mathrm{MW}$ and efficiency at 46-48\%.

The process air or air-steam gasification of the most promising technologies to organize using circulating fluidized bed. This technology is being promoted on the boiler with direct burning of coal.

In 2009, Poland was put into operation the first unit of $460 \mathrm{MW}$ CFB boiler manufactured by Foster Wheeler, designed for supercritical steam (265 bar / $833 \mathrm{~K})$. This block provides the world's best performance for units with a CFB boiler $-43.3 \%$, which, coupled with very low emissions meet the requirements of the EU directive on large combustion fuels [2].

The efficiency of the CFB boiler depends on a number of factors affecting the distribution, burning, internal and external circulation of the particles. Because the quality design of powerful energy stakes 


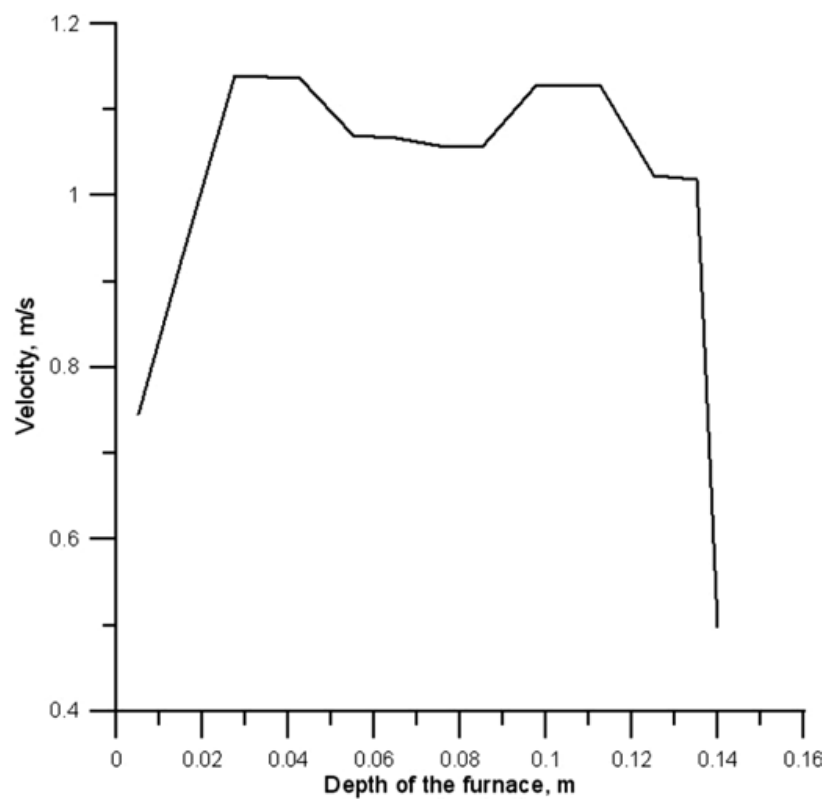

Figure 2. Changing the flow rate of the depth of the furnace at a height of $3.5 \mathrm{~m}$.

CFB largely depends on the presentation and analysis of gas-dynamic processes. Their most promising research, taking into account the level of development of modern computer technology, using the methods of numerical analysis, with a number of well-known advantages in relation to the theoretical and experimental methods.

An example is given numerical study of gas dynamics based on the model of the boiler furnace with circulating fluidized bed height of $5.4 \mathrm{~m}$, a diameter of $0.14 \mathrm{~m}$. The blower speed lower $-10.5 \mathrm{~m} / \mathrm{s}$, fuel consumption $-0.02 \mathrm{~kg} / \mathrm{s}$.

\section{Mathematical model}

The numerical description of the motion of polydisperse fuel particles in the boiler furnace has been done with the aid of the Lagrangian approach. The basic idea of this technique for representation of the disperse phase behavior lies in the fact that the entire spectrum of the particles of the coal-dust fuel supplied to the furnace chamber is partitioned into $N$ groups. It is assumed here that the behavior of each group of particles may be characterized by the behavior of its representative - the trial single marker particle. That is the properties, which has the marker particle at the present moment of time, are extended for all particles of the group, which are represented by the marker particle [3-5].

To determine the location, velocity components, mass and temperature of fuel particlesrepresentatives at their motion within the furnace volume and the inverse influence of the disperse phase on carrying medium, the approach was used in the present work, which was based on the application of formulas for the approximate analytic solution of the system of ordinary differential equations for the marker particle parameters.

\section{Results and discussion}

Figure 1 presents the results of a numerical calculation model of the boiler furnace with circulating fluidized bed using a software package FIRE 3D [3, 4, 6]. 


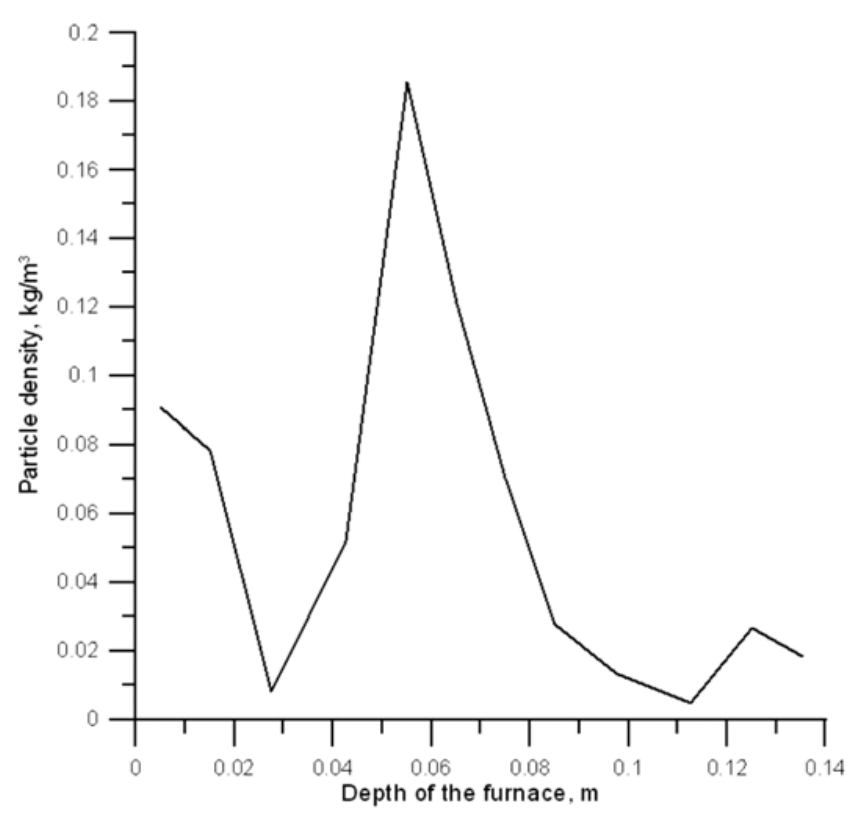

Figure 3. Changing the concentration of particles in the depth of the furnace at a height of $3.5 \mathrm{~m}$.

In the lower part of the furnace there are maximum values of the velocities. With increasing height the flow rate decreases. Since there is intense accumulation of particles at a height of 2 to $4 \mathrm{~m}$ (Fig. 1). In height the furnace can be divided into three sections with a flow rate of $15-20 \mathrm{~m} / \mathrm{s}, 7.5-15 \mathrm{~m} / \mathrm{s}$ and $1-7,5 \mathrm{~m} / \mathrm{s}$. When this occurs the start of accumulation of the solid phase at a flow rate decrease to $7.5 \mathrm{~m} / \mathrm{s}$.

Figure 2 shows the change in velocity over the depth of the furnace at a height of $3.5 \mathrm{~m}$. Near the walls of the furnace velocity values close to zero. At a distance of $20 \mathrm{~mm}$ from the walls of the flow rate is increased to $1.12 \mathrm{~m} / \mathrm{s}$, while the central portion is reduced to $1.08 \mathrm{~m} / \mathrm{s}$. In the central part of the furnace is intensively transported particles at a given height (Fig. 3).

The concentration of particles in the horizontal section of the furnace at a height of $3.5 \mathrm{~m}$ in the middle zone reaches a maximum value, and is $0.18 \mathrm{~kg} / \mathrm{m}^{3}$. In the peripheral areas of the concentration decreases and contact the walls increases to $0.08 \mathrm{~kg} / \mathrm{m}^{3}$. This fact may indicate the presence of internal circulation of particles. In the central area of the particles rise up the walls of the furnace and slowly fall to the bottom.

\section{Conclusions}

The proposed numerical approach allows to obtain a visual picture and integral characteristics of the physical processes in the furnaces of a circulating fluidized bed.

By analyzing the numerical results it can be noted that the flow rate decreases sharply at a height approximately $2 / 3$ of the total height due to the accumulation of solid particles above this area and reverse the movement of particles from the walls.

The results suggest the need for revision of the particulate composition of the fuel or change of the design model of the furnace. Because the gas-dynamic processes in the model obtained is not typical for the stable operation of boilers with circulating fluidized bed. 


\section{References}

[1] L.I. Korobeynikova, A.Y. Gil. Bulletin of the Tomsk Polytechnic University, 316, 105 (2010)

[2] G.A. Ryabov, O.M. Folomeev, D.A. Sankin, K.V. Khaneev, I.G. Bondarenko and D.A. Mel'nikov. Power Technology and Engineering, 44, 137, (2010)

[3] A.V. Gil, A.V. Starchenko. Thermophysics and Aeromechanics, 19, 503 (2012)

[4] Gil A.V., Zavorin A.S., Starchenko A.V., Obukhov S.V. Power Technology and Engineering, 45, $42(2011)$

[5] A.M. Bubenchikov and A.V. Starchenko, Numerical Models of the Dynamics and Combustion of Aerodisperse Mixtures in Channels, (Tomsk State Univ., Tomsk, 1998)

[6] A.S. Zavorin1, A.V. Gil1, P.S. Khaustov1, R.B. Tabakaev1 and D.A. Buslov. IOP Conf. Series: Materials Science and Engineering 66012038 (2014) 